transient ischaemic attacks could be increased with low doses of phenytoin. ${ }^{20}$ This suggests that the possibility of increasing low concentrations of high density lipoprotein cholesterol with safe doses of anticonvulsants should also be considered in patients who run a high risk of coronary heart disease.

This study was supported by grants from the Paulo and Paavo Nurmi foundations, Helsinki, Finland.

\section{References}

1 Miller GJ. High density lipoproteins and atherosclerosis. Annu Rec .Med 1980:31:97-108. 2 Kannel WB. High-density lipoproteins: epidemiologic profile and risks of coronary artery disease. Am f Cardiol 1983:52 (suppl 6:9-12.

3 Brunzell JD, Sniderman AD, Albers JJ. Kwiterovich PO, Jr. A poproteins B and A-1 and coronary artery disease in humans. Arteriosclerosis 1984;4:79-83.

4 Nikkilä EA, Kaste M, Ehnholm C. Viikari J. Increase of serum high-density lipoprotein in phenvtoin users. Br Med 7 1978;ii:99.

5 Wallace RB. Hunninghake DB, Reiland S, et al. Alterations of plasma high-density lipoprotein cholesterol levels assckiated with consumption of selected medications. The lipid research clinics prograss assiciated with consumption of selected medication

6 Luoma PV, Myllylä VV, Hokkanen E. Relationship between plasma high-density lipoprotein cholesterol and anticonvulsant levels in epileptics. $\mathcal{f}$ Cardiocasi Pharmacol 1982;4: 1024-7.

7 O'Neill B, Callaghan N, Stapleton M, Molloy W' Serum elevation of high density lipoprotein
HDL cholesterol in epileptic patients taking carbamazepine or phenytoin. Acta Neurol Scand $1982 ; 65: 104-9$.

8 Berlit P, Krause K-H, Heuck CC, Schellenberg B. Serum lipids and anticonvulsants. Acta Neurol Scand 1982;66:328-34.

9 Linden V. Myocardial infarction in epileptics. Br. Med 7 1975;ii:87.

9 Linden V. Mvocardial infarction in epileptics. Br. Med f 1975:11:87.

11 Annegers JF, Elveback LR, Labarthe DR. Hauser WA. Ischemic heart disease in patients with epilepsy. Epilepsia 1976;17:11-4.

12 Hauser WA, Annegers JF, Elveback LR. Mortality in patients with epilepsy. Epilepsia $1980 ; 21: 399-412$.

13 Annegers JFG, Hauser WA, Shits SB. Heart disease mortality and morbidity in patients with epilepsy. Epilepsia 1984:25:699-704

14 Fleiss JL. The analysis of data from matched samples. In: Fleiss JL, ed. Statistical methods for rates and proportions. 2nd ed. New York: John Wiley and Sons, 1980:112-9.

15 Durrington PN. Effect of phenobarbitone on plasma apolipoprotein B and plasma high-densitylipoprotein cholesterol in normal subjects. Clin Sci 1979;56:501-4.

16 Malherbe C, Burrill KC, Levin SR, Karam JH, Forsham PH. Effect of diphenylhydantoin on insulin secretion in man. $N$ Engl f Med 1972;286:339-42.

17 Perry-Keene DA, Larkins RG, Hevma P, Peter CT, Ross D, Sloman JG. The effect of long-term diphenvlhydantoin therapy on glucose tolerance and insulin secretion: a controlled trial. Clin Endocinol 1980;12:575-80

18 Stout RW. The role of insulin in atherosclerosis in diabetics and nondiabetics: a review. Diabetes $1981: 30: 54-7$.

19 Pyörälä $\mathrm{K}$. Relationship of glucose tolerance and plasma insulin to the incidence of coronary heart disease: results from two population studies in Finland. Diabetes Care 1979;2:131-41.

20 Kaste M, Muuronen A, Nikkilä EA, Neuvonen PJ. Increase of low serum concentrations of highdensity lipoprotein (HDL) cholesterol in TIA-patients treated with phenytoin. Stroke 1983; 14:525-30.

Accepted 21 August 1985

\title{
Comparison of response rates to a postal questionnaire from a general practice and a research unit
}

\author{
W C S SMITH, I K CROMBIE, P D CAMPION, J D E KNOX
}

\begin{abstract}
A postal questionnaire study was carried out in an urban general practice to determine the effect of the introductory letter being sent by the participants' own general practitioner compared with that from a letter sent directly from a research unit. By sequential sampling 409 individuals aged between 40 and 59 were assigned to one of two groups. The people in one group were written to by their own general practitioner and those in the other by a doctor from a research unit. Husbands and wives were paired and were always sent the same letter. A second letter was sent to nonresponders after one month.

The response rate to the general practitioner was significantly higher than that to the doctor in the research unit $85 \%$ compared with $75 \%$ ) and differed by age and sex. The results have important implications for other research workers and suggest that general practitioners are in a key position in the conduct of medical and epidemiological research.
\end{abstract} Cardiovascular Epidemiology Unit, Ninewells Hospital and Medical School,
Dundee DD1 9SV

W C S SMITH, MPH, MFCM, epidemiologist

I K CROMBIE. BSC, PHD, senior statistician

Medical School Teaching Practice, Dundee

P D CAMPION, MRCP, MRCGP', lecturer in general practice

J D E KNOX, MD, FRCGP', professor of general practice

Correspondence to: Dr Smith

\section{Introduction}

Questionnaires are in widespread use as a tool in medical research for the collection of data. In most study designs it is important to obtain a high response rate from the selected study population to avoid bias. The results of some studies have shown important differences between responders and non-responders.' 2 Thus responders in a study with a low response rate are unlikely to be representative of the study population. Studies therefore require high response rates or need information about the non-responders so that the nature of the bias may be determined.

As part of a series of pilot studies in preparation for a large, national study of coronary heart disease in Scotland, the Scottish Heart Health Study, a postal questionnaire was sent to individuals aged between 40 and 59 years. The aim was to test a questionnaire design and to investigate the nature and size of the effect of the participant's own general practitioner sending the introductory letter compared with the effect of the letter coming directly from a research unit.

\section{Methods}

The participants were selected from the patients who were registered with an urban general practice that has been described." The names and addresses of all patients aged 40 to 59 were obtained from a computer listing from the Tavside master patient index. ${ }^{+}$Twenty six patients were excluded because the general practitioners considered them unsuitable for the study on the grounds of limited knowledge of the English language or mental or physical illness.

The 409 patients who were identified were assigned by sequential sampling to one of two groups. One group was written to by the general 
practitioners, the other by a doctor from the research unit. The letters from each source were on appropriately headed notepaper and requested the patient to complete and return a questionnaire in an enclosed, stamped addressed envelope to the research unit. The questionnaires were numbered serially and contained no details of name or address. The questionnaire was 20 pages in length and asked questions about heart disease and, for example, smoking, exercise, diet, and personality type.

Because of the possible problems of two persons in one household receiving the same letter from different sources, husband and wife pairs were identified by scrutinising the patient listing by the practitioners. A total of 102 pairs were identified and each pair received a letter from the same source, although the sources were randomised between pairs.

\section{Results}

The 409 letters from the research unit and the general practice were posted on the same day, and table I gives the details of the return of questionnaires by the patients or the GPO. After a four week period when the flow of returns had almost stopped a second letter was sent to the non-responders (excluding those to whom first letters were returned by the GPO). Overall, $65 \%$ of patients responded to letters from the research unit but $81 \%$ to a letter from their general practitioner. As table I shows, however, there was a difference in the number of letters returned by the GPO between the research unit and the general practitioner ( $13 \%$ compared with $5 \%$ ). Since letters returned by the GPO tell us nothing about patient response by source of letter, and these returns could bias the results, they were removed from all subsequent analyses. This practice has been adopted in the reporting of other studies on response rates. ${ }^{6}$ Modified in this way the response rates still show a considerable advantage to the general practitioner of $85 \%$ compared with $75 \%(\mathrm{p}<0.05)$.

There was a higher response to the general practitioner's letter from both

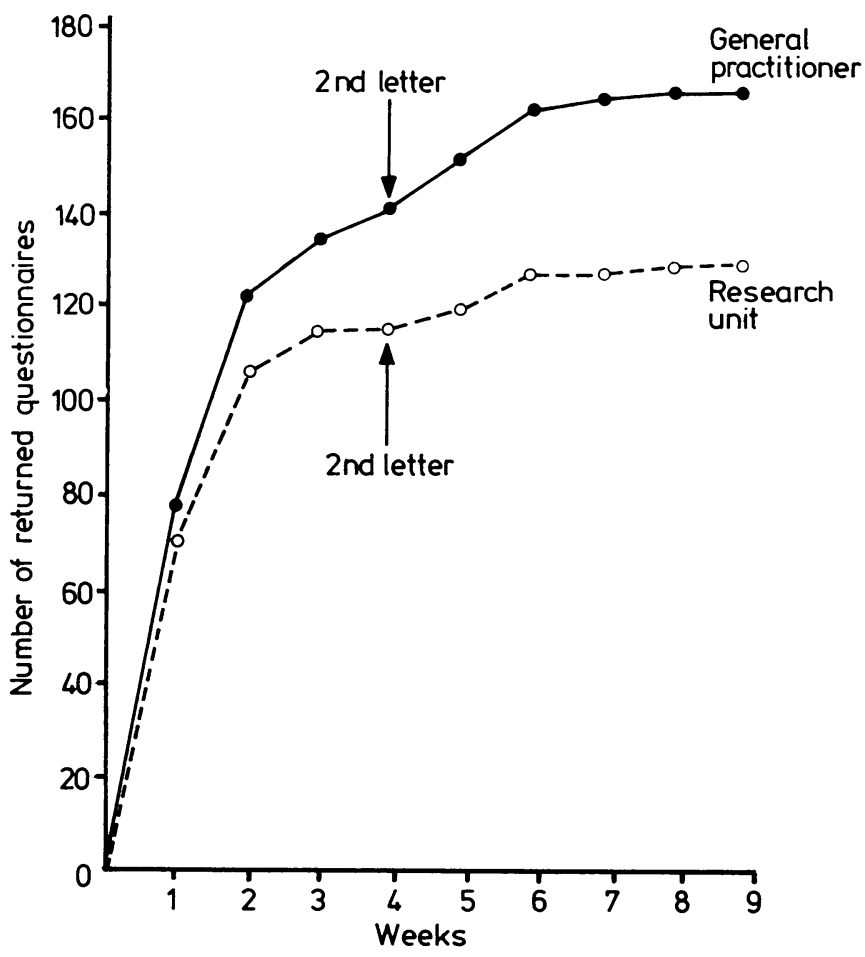

Response to the questionnaire from the general practitioner and from the research unit.

TABLE I-Responses by source of letter

\begin{tabular}{|c|c|c|c|c|c|c|}
\hline & \multicolumn{3}{|c|}{ Research unit } & \multicolumn{3}{|c|}{ General practitioner } \\
\hline & $\begin{array}{c}\text { No of } \\
\text { letters sent }\end{array}$ & $\begin{array}{l}\text { No that } \\
\text { GPO } \\
\text { returned }\end{array}$ & $\begin{array}{l}\text { No of } \\
\text { questionnaires } \\
\text { returned }\end{array}$ & $\begin{array}{c}\text { No of } \\
\text { letters } \\
\text { sent }\end{array}$ & $\begin{array}{l}\text { No that } \\
\text { GPO } \\
\text { returned }\end{array}$ & $\begin{array}{l}\text { No of } \\
\text { questionnaires } \\
\text { returned }\end{array}$ \\
\hline First letter & 203 & 23 & 118 & 206 & 7 & 139 \\
\hline Second letter & 62 & 4 & 14 & 60 & 3 & 27 \\
\hline
\end{tabular}

TABLE II-Age and sex differences in response rates (excluding letters returned by the GPO)

\begin{tabular}{|c|c|c|c|c|c|}
\hline \multirow[b]{2}{*}{ Source of letter } & \multicolumn{2}{|c|}{ No of men } & \multicolumn{2}{|c|}{ No of women } & \multirow{2}{*}{$\begin{array}{l}\text { Total } \\
\text { No }\end{array}$} \\
\hline & $40-49$ years & $50-59$ years & $40-49$ years & $50-59$ years & \\
\hline \multicolumn{6}{|l|}{ Research unit: } \\
\hline Returned & 21 & 39 & 30 & 42 & 132 \\
\hline Sent & 32 & 52 & 42 & 50 & 176 \\
\hline Response rate (\%) & 66 & 75 & 71 & 84 & 75 \\
\hline \multicolumn{6}{|l|}{ General practitioner: } \\
\hline Returned & 35 & 50 & 32 & 49 & 166 \\
\hline Sent & 42 & 57 & 41 & 56 & 196 \\
\hline Response rate $(\%)$ & 83 & 88 & 78 & 88 & 85 \\
\hline
\end{tabular}

men and women and in the two age groups 40-49 and 50-59 (table II). The letter from the general practitioner achieved a response of roughly $80 \%$ for each of the four age and sex groups. Compared with this the letter from the research unit had a slightly reduced response among women but less among men. The largest difference, for men aged $40-49$, was $18 \%$

A plot of the time course of the receipt of replies shows that about half were received within one week of posting and that the response had almost stopped by the third week (figure). The second letter of invitation stimulated response for a further two weeks. The higher response to the general practitioner's letter was evident from the first week, and despite already being at a higher level the second letter produced a larger additional response (14\% compared with $8 \%$ ).

The husband-wife pairs behaved with almost complete consistency since either both replied or both did not reply: in 89 pairs both replied, in five pairs the husband only replied, and in three the wife only replied. The pattern was similar for letters from both sources. For the remaining couples the GPO returned four pairs of letters and for the fifth the husband's letter was returned by the GPO, whereas that of the wife was answered and returned. Compared with its overall rate the letter from the research unit elicited a slightly better response from married couples, where $80 \%$ of the 90 individuals ( 45 pairs) replied. For the letter from the general practitioner, however, the response among married couples was about the same- $83 \%$ of the 104 individuals ( 52 pairs).

\section{Discussion}

The response rate to this formidable, 20 page questionnaire, regardless of the mode of approach to the subject, was $73 \%$ overall, or $80 \%$ when items returned by the GPO were excluded. A 
significantly better response rate $(85 \%)$ was found when the covering letter was written by the subject's own general practitioner than when it was written by the researcher from a research unit in a hospital $(75 \%)$. Factors affecting the response to a postal survey have been reviewed by Alderson ${ }^{-}$and Scott. * Although common sense might suggest it, there is no clear evidence on whether the length of the questionnaire influences response. None the less, it is encouraging that this questionnaire, which takes roughly 40 minutes to complete, was met with such a high response rate.

The differences in the GPO returns between the general practitioner and the research unit is hard to explain except as a chance occurrence. All the envelopes were identical, with the same return to sender address, and all were returned unopened. It was thus considered appropriate to exclude these returns from the GPO from the main analyses. The GPO return rate of $9 \%$ is consistent with our experience in urban areas in Scotland.

The response by age and sex to the practitioner's letter (table II) is consistent around the $80 \%$ level, whereas that to the research unit was poorer in the younger age groups, with the response rate for women being better than for men. Only in the older women did the response to the research unit approach that to the practitioner.

The explanation of these observations must be speculative, but the implicit professional relationship existing between the general practitioner and the patients on his list can be invoked as a likely reason for the higher response. This may be either because the patients feel they know him better than the anonymous researcher or because they feel an obligation towards him. This attitude has been explored by Cartwright, who expressed concern that doctors may be in a position to apply pressure on their patients to cooperate. ${ }^{9}$ There was no overt suggestion in this study of an obligation to respond, but the possibility remains and should be borne in mind by researchers using this approach.

\section{Conclusions}

The results of this study show an important and statistically significant favourable effect of the approach in a research study coming from the individual's own practitioner compared with direct approaches from a research department. As a result of this study all prospective participants in the Scottish Heart Health study are initially approached by a letter signed by their own practitioner. These results have important implications for other research units and research workers. They also illustrate that general practitioners are in a key position to carry out research work, ${ }^{10}$ although possession of an accurate age-sex register is a necessity.

We thank Elizabeth Callan and Paul Salmon for their help and Professor $\mathrm{H}$ Tunstall Pedoe for his useful comments on the manuscript.

\section{References}

1 Sheikh $\mathrm{K}$, Mattingly S. Investigating non-response bias in mail survevs. $\mathcal{F}$ Epidemiol Community Health 1981;35:293-6.

Health 1981;35:293-6.
2 Bergstrand R, Vedin A, Wilhelmsson C, Wilhelmsson L. Bias due to non-participation and Bergstrand $R$, Vedin $A$, Wilhelmsson $C$, Wilhelmsson $L$. Bias due to non-partic
heterogeneous sub-groups in population surveys. $\mathcal{f}$ Chronic Dis 1983;36:725-8.

3 Smith WCS, Knox JDE. Assessment of the immunization status of practice children under five years of age. IR Coll Gen Pract 1984;34:160-2.
y

4 Tayside Health Board. The Tayside master patient index. Dundee: Tayside Health Board, 1978.

Markush RE. The relation of form length to response in mailed epidemiologic enquiries. Public Health Rep 1966;81:191-5.

6 Kaplan S, Cole P. Factors affecting response to postal questionnaires. British fournal of Preventive and Social Medicine 1970;24:245-7.

7 Alderson M. An introduction to epidemiology. London: Macmillan, 1976.

8 Scott C. Research on mail surveys. Joumal of the Royal Statistical Society A 1961;124:143-95.

9 Cartwright A. Health surveys in practice and potential: a critical view of their scope and methods. London: King Edward's Hospital Fund, 1983.

10 Howie JGR. Research in general practice. London: Croom Helm, 1979.

(Accepted 21 August 1985)
Live yoghurt seems to be recommended to increase normal bacteria in the bowel and prevent "thrush" infection. Is there a risk that the abnormal organisms present in unpasteurised milk such as brucella, campylobacter, and Salmonella would also be present in yoghurt?

The milk used for making yoghurt is treated before fermentation by steaming for five minutes or heating to $95^{\circ}$ for 10 minutes. This treatment, which is necessary to induce the formation of the characteristic gel structure, is sufficient to kill off any vegetative pathogens. Yoghurt is, therefore, not a source of brucellas, campylobacter, or salmonellas and may quite safely be used for oral or vaginal administration.-R FULL.ER, Food Research Institute, Reading.

A 65 year old patient has suffered from severe headaches every day for the past 10 years. They are mainly frontal and wake him several times at night. He has been extensively investigated and no cause found and he has tried many treatments without good effect. The only remedy that gives him immediate relief is strong tea and the relief lasts for about four hours. Assuming addiction, he has tried periods without tea, but the headaches do not wear off after withdrawal. Is this a recognised phenomenon and is there any known explanation?

From the information given I can only speculate about the diagnosis and this makes the interpretation of the response to tea difficult. The fact that the patient is awakened through the night by pain would incline me towards a diagnosis of one of the variants of migrainous neuralgia - either the chronic variety ${ }^{1}$ or, if the pain is predominantly unilateral, the rare variant called chronic paroxysmal hemicrania. ${ }^{2}$ This is more common in women and the headache is of short duration, recurring frequently through day and night. There is usually a dramatic response to indomethacin, whereas the standard treatments for migrainous neuralgia, such as ergotamine, methysergide, propanolol, and lithium, are unhelpful. The alternative diagnosis I would consider is that of chronic tension headache, but this rarely wakes the patient from sleep unless it is a manifestation of a severe psychiatric disturbance such as depression.

"Tea responsive headaches" are not well recognised, though I can conceive of two possible explanations. Strong tea contains a high concentration of caffeine (perhaps as much as 100-200 mg per cup) and I presume this is producing the therapeutic response. This amount might produce significant cerebral vasoconstriction (a reason for including caffeine in antimigraine preparations) and this might improve the pain of migrainous neuralgia in a similar manner to ergotamine. An alternative explanation is that the improvement is a non-specific response to the central nervous system stimulant effects of caffeine, although I think this is less likely. $-\mathrm{N}$ W F CARTLIDGE, consultant neurologist and senior lecturer in neurology, Newcastle upon Tyne.

1 Lance JW. Headache. Ann Neurol 1981;10:1-10.

2 Sjaastad O, Dale I. Evidence for a new treatable headache entity. Headache 1974;14:105-8.

How can I best approach the problem of a severely handicapped 12 year old boy who is now becoming sexually mature as is evident by erection and general arousal when in the presence of females? This increasingly stimulates him either to masturbate or to rub himself against a convenient object. For religious reasons the mother, although adaptable and understanding, has been unable to accept the advice of one of the team managing the child that he should be "allowed to get on with it in his own room." The main problem is that the child is not entirely aware whether or not he is in his own room, and not all visitors are as understanding as the giver of this advice.

The family might try to apply "contingency management with time out." With this approach, whether visitors are present or not, as soon as he masturbates anywhere outside his room the boy would be gently removed from company, taken to his room and told why, and ignored for the next 15 minutes without having access to any rewards. Equally important, he should be fulsomely rewarded when he does not masturbate outside his room, and again be told why. The family could role rehearse this approach with a stooge a few times, and also role play having to explain to visitors what is being done, so that there is better explanation to them and less embarrassment if the boy has to be removed when visitors are present. In addition, as the mother's anxiety is partly religious in origin, she might speak to a priest from her denomination whom she especially respects to learn that the behaviour is probably not sinful in someone so severely handicapped; her anxiety might then reduce, enabling her to manage the problem more easily._ISAAC MARKS, professor of psychiatry, London. 